\title{
Nanocomposites of Polypropylene/Nano Titanium Dioxide: Effect of Loading Rates of Nano Titanium Dioxide
}

\author{
Deniz AYDEMIR ${ }^{1 *}$, Gulsen UZUN ${ }^{1}$, Havva GUMUŞ ${ }^{1}$, Sonnur YILDIZ ${ }^{1}$, Sultan GUMUŞ ${ }^{1}$, \\ Timucin BARDAK ${ }^{2}$, Gokhan GUNDUZ ${ }^{1}$
}

\author{
${ }^{1}$ Department of Forest Industrial Engineering, Faculty of Forestry, Bartin University, 74100, Bartin, Turkey \\ ${ }^{2}$ Department of Furniture and Decoration, Technical Collage, Bartin University, 74100, Bartin Turkey \\ cross $^{\text {ref }}$ http://dx.doi.org/10.5755/j01.ms.22.3.8217
}

Received 20 September 2014; accepted 10 April 2015

\begin{abstract}
$\mathrm{TiO}_{2}$ filled Polypropylene (PP) nanocomposites were prepared with a single screw extruder and then by injection molding of the blends. Water absorption, density, mechanical properties, morphological characterization, FTIR analysis, and the thermal stabilities of the nanocomposites were investigated. The results showed that water absorption decreased and density increased as the amount of nano- $\mathrm{TiO}_{2}$ added increased. The mechanical properties improved for all formulations with the addition of nano- $\mathrm{TiO}_{2}$, except for the tensile modulus of elasticity and the izod impact strength. Thermogravimetric analysis (TGA) indicated that the thermal stability of the nanocomposites improved as the amount of nano- $\mathrm{TiO}_{2}$ increased. The melting and decomposition peaks of DTA increased as nano- $\mathrm{TiO}_{2}$ was added. The differential scanning calorimetry (DSC) results showed that the melting temperature $(\mathrm{Tm})$ increased with the addition of nano- $\mathrm{TiO}_{2}$. Scanning electron microscopy (SEM) images of the nanocomposites showed uniform dispersion for $0.5,1$, and $2 \%$ $\mathrm{TiO}_{2}$, but some agglomerations were found on the surfaces and in the fractured sides of the nanocomposites with $4 \%$ $\mathrm{TiO}_{2}$. The agglomerates were determined by SEM mapping. The changes in the chemical structure of the nanocomposites were determined with Fourier transform infrared (FTIR) spectroscopic analysis. The FTIR results showed that the chemical structures of the composites were similar and that there were no major differences between the composites.

Keywords: polypropylene, $\mathrm{TiO}_{2}$, nanocomposites, mechanical properties, thermal stability.
\end{abstract}

\section{INTRODUCTION}

Polymers are used in many areas, such as automotive, electronics, and different construction equipment. Generally, they are used after being reinforced with various nano fillers to provide unique properties, such as aspect ratio, low weight, and easy formability [1]. These kinds of composites that are reinforced with nano-scale fillers are called 'nanocomposites.' In recent years, nanocomposites have attracted the attention of many researchers because of the significant enhancements in many properties at low loadings [2, 3]. Many researchers have investigated different polymers with various fillers. Polypropylene (PP) is one of the most extensively used polymers due to its ease of processing and low cost. It is used in many applications, such as packaging, textiles, plastics, reusable boxes, laboratory equipment, automotive components, and others. Many types of particles have been used to improve PP's properties, such as its UV resistance, its mechanical properties, and its stability. Titanium dioxide particles have been used for this purpose because they enhance UV stabilization, strength, and antibacterial activity $[4,5]$. Titanium dioxide $\left(\mathrm{TiO}_{2}\right)$ is an inexpensive and non-toxic semiconductor, and it enhances the properties of polymers, allowing the development of new nanocomposites with enhanced behaviours [6].

Altan and Yildirim [4] investigated the properties of $\mathrm{PP} / \mathrm{TiO}_{2}$ nanocomposites, and their results indicated that composites with $\mathrm{TiO}_{2}$ had better mechanical properties

\footnotetext{
* Corresponding author. Tel.: +90 (378) 223 5077; Fax: +90 (378) 223 5062, E-mail address: denizaydemir@bartin.edu.tr (D. Aydemir)
}

than pure PP. The mechanical properties of the composites varied according to the dispersion, and low loadings with uniform dispersion were found to produce better mechanical properties. Yang et al. [7] also studied the mechanical properties of $\mathrm{PP} / \mathrm{TiO}_{2}$ nanocomposites, and their results indicated that the mechanical properties improved with nano- $\mathrm{TiO}_{2}$ particles in the polymer. Zohrevand et al. [8] worked on the thermal stability and mechanical properties of $\mathrm{PP} / \mathrm{TiO}_{2}$ nanocomposites. The results showed that the thermal properties of the nanocomposites were affected significantly by the dispersed particles. The $\mathrm{TiO}_{2}$ particles decreased the elastic modulus and yield strength of the nanocomposites. Micromechanical analyses showed that there was enhanced interaction between the organic and inorganic phases of the nanocomposites. In other studies of polypropylene $/ \mathrm{TiO}_{2}$ blends, the mechanical properties of the blends were found to be improved by the addition of nano- $\mathrm{TiO}_{2}$. Incorporation of nanoparticles improves the thermal stability of PP. DSC analysis also showed that an improvement in crystallinity was observed when the nano- $\mathrm{TiO}_{2}$ particles were added [9]. In this study, it was investigated the effects of different loadings of hydrophilic, nano-sized titanium dioxide particles (nano- $\mathrm{TiO}_{2}$ ) on the thermal stability, mechanical properties, and morphological characteristics of polypropylene (PP) composites.

\section{MATERIALS AND METHODS}

\subsection{Materials}

Polypropylene (EH241) was supplied by PETKIM, Inc., Turkey. The properties of the PP are listed in Table 1. 
Nano-sized titanium dioxide (nano- $\mathrm{TiO}_{2}$ ) was used to reinforce the PP. Nano- $\mathrm{TiO}_{2}$ was supplied by Mknano, Inc., Canada. The nano- $\mathrm{TiO}_{2}$ was a powder with particle sizes ranging from 15 to $30 \mathrm{~nm}$ (Fig. 1).

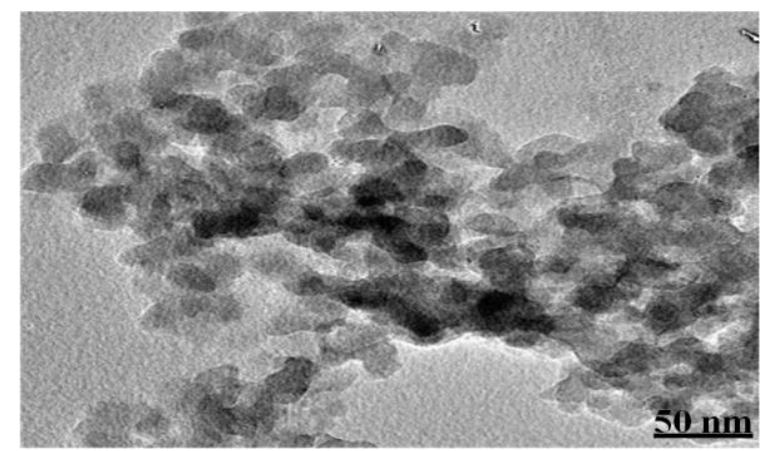

Fig. 1. TEM micrographs of $\mathrm{TiO}_{2}$ nanoparticles

$\mathrm{PP}$ and nano- $\mathrm{TiO}_{2}$ were stored in plastic boxes after being dried in an oven at $103 \pm 2{ }^{\circ} \mathrm{C}$ to obtain a moisture content of less than 1 percent.

Table 1. Properties of polypropylene (PP)

\begin{tabular}{|l|c|}
\hline Properties & Values \\
\hline Melt flow index, g/10 $\min \left(\right.$ at $\left.230^{\circ} \mathrm{C} / 2.16 \mathrm{~kg}\right)$ & 5 to 20 \\
\hline Density, $\mathrm{g} / \mathrm{cm}^{3}$ & 0.92 \\
\hline Water absorption, $\%$ & 0.1 \\
\hline Processing Temperature, ${ }^{\circ} \mathrm{C}$ & $160-170$ \\
\hline Tensile modulus, $\mathrm{MPa}$ & 35 \\
\hline Flexural modulus, $\mathrm{GPa}$ & 1.5 \\
\hline Izod Impact, notched, $\mathrm{kJ} / \mathrm{m}^{2}$ & 2 \\
\hline
\end{tabular}

\subsection{Preparation of $\mathrm{PP} / \mathrm{TiO}_{2}$ nanocomposites}

In this study, PP was used as the matrix polymer and $\mathrm{TiO}_{2}$ particles were used as nano fillers. The loading ratios of nano- $\mathrm{TiO}_{2}$ were $0.5,1,2$, and $4 \mathrm{wt} \%$, respectively. The dried nano- $\mathrm{TiO}_{2}$ particles and the $\mathrm{PP}$ were extruded at $50 \mathrm{rpm}$ through a single-screw extruder according to ASTM D 638-03 and D 790-03. In extruder, the zone temperatures ranged from 160 to $170{ }^{\circ} \mathrm{C}$; the screw speed was $50 \mathrm{rpm}$; the melt pressure at the extruder varied between 5 and 10 bars, depending on the blends of the materials; and the output of the material was $1 \mathrm{~kg} / \mathrm{h}$. During the extrusion mixing process, the polymer-filler melts were blended, and, then, the compounding was completed. The extrudate, in its molten state, was cooled and solidified in a water-cooling system while being pulled with an end drive conveyors. Then, the solidified extrudate was pelletized with a pelletizer, and the pellets were injection molded to obtain the test samples. The processing temperature and melt pressure were used to $165^{\circ} \mathrm{C}$ and 20 bar during injection molding.

\subsection{Methods of analysis}

Water Absorption (WA) for a week hours was determined under controlled environment according to ASTM D 1037. Density was measured by a water displacement technique according to ASTM D792-98. The tensile strength (TMOR) and tensile moduli of elasticity (TMOE) were conducted according to ASTM D 638-03 Type I. The flexural strength (FMOR) and flexural moduli of elasticity (FMOE) of the composites were measured using a Zwick with a $5 \mathrm{kN}$ load cell. The tests were conducted according to ASTM D 790-03 using same Zwick tester. Izod impact tests (IIS) were conducted according to ASTM D 256-06 with a Resil $50 \mathrm{~B}$ impact tester. Thermal properties were determined using a TGA/DTG. Degradation temperatures at $10 \%$ weight loss $\left(T_{\% 10}\right)$ and $50 \%$ weight loss $\left(T_{\% 50}\right)$, maximum degradation temperature in the derivative thermogravimetry peaks $\left(D T G_{\max }\right)$, and mass loss of the samples in the TGA cures were measured. DSC analysis was performed on a DSC 2920 analyser. After DSC analysis, melting temperature $(T m)$, melting enthalpy $(\Delta H m)$, and crystallinity $(X c)$ were determined. Morphological properties of the samples under nitrogen were observed with a scanning electron microscope (SEM) with an accelerating voltage of $5 \mathrm{kV}$. Dispersion of nano- $\mathrm{TiO}_{2}$ in the matrix was determined with SEM mapping. FTIR Spectroscopy was used to determine the changes in the chemical structures of all of the samples. Each spectrum was recorded in the range of $700-4000 \mathrm{~cm}^{-1}$ with a resolution of $2 \mathrm{~cm}^{-1}$. Statistical Analysis was performed with One-way analysis of variance (ANOVA) at the $99 \%$ confidence level. The Duncan test was used to determine the difference between groups. The important differences between formulations were shown with letters, such as A, B, C, and D.

\section{RESULTS AND DISCUSSION}

Table 2 shows the WA and density of the nanocomposites. The WA results showed that all of the composites had different behaviours during water absorption. The neat PP was found to have the maximum WA value. The WA values of the composites with nano$\mathrm{TiO}_{2}$ were less than that of the neat PP. But the WA values of the nanocomposites found to increase as amount of nano- $\mathrm{TiO}_{2}$ was increased from 0.5 to $4 \%$. This can be explained by the fact that the nano- $\mathrm{TiO}_{2}$ had a hydrophilic property. Therefore, increasing the amount of nano- $\mathrm{TiO}_{2}$ increased the water absorption of the nanocomposites. As seen as the densities of the composites, the densities increased when the amount of nano- $\mathrm{TiO}_{2}$ increased, except for the composite with $0.5 \%$ nano- $\mathrm{TiO}_{2}$. The maximum and minimum increases in the densities were determined occur in the $1 \%$ nano- $\mathrm{TiO}_{2}$ and the $4 \%$ nano- $\mathrm{TiO}_{2}$, respectively. The densities have a significant effect on the mechanical properties, which affected many properties of the composites [10]. According to the variance analysis, the Duncan tests indicated that the differences between the densities of the composites were statistically significant. When the density values increased, the mechanical properties of the composites also increased. The adding nano- $\mathrm{TiO}_{2}$ provided some improvement in the mechanical properties of neat PP. When filler ratio was increased, tensile strength increased; but the tensile modulus of elasticity was determined to decrease when nano- $\mathrm{TiO}_{2}$ was added. The highest and lowest values of the tensile strength in the composite were determined to $4 \%$ nano$\mathrm{TiO}_{2}$ and $0.5 \%$ nano- $\mathrm{TiO}_{2}$, respectively. The highest and lowest values of tensile modulus of elasticity in the composite occurred to $0.5 \%$ nano- $\mathrm{TiO}_{2}$ and $4 \%$ nano$\mathrm{TiO}_{2}$, respectively. The highest increase of tensile strength in the composite was found to be $6.7 \%$ for the $4 \%$ nano$\mathrm{TiO}_{2}$. 
Table 2. Density, water absorption, mechanical properties of the nanocomposites

\begin{tabular}{|c|c|c|c|c|c|c|c|}
\hline Samples & $\begin{array}{l}\text { Density, } \\
\mathrm{g} / \mathrm{cm}^{3}\end{array}$ & Water absorption, $\%$ & $\begin{array}{c}\text { TMOR, } \\
\text { MPa }\end{array}$ & TMOE, MPa & $\begin{array}{c}\text { FMOR, } \\
\text { MPa }\end{array}$ & $\begin{array}{c}\text { FMOE, } \\
\text { MPa }\end{array}$ & IIS, $\mathrm{kJ} / \mathrm{m}^{2}$ \\
\hline $\mathrm{PP}$ & $0.90 \mathrm{AB}$ & $1.40 \mathrm{BC}$ & $29.8 \mathrm{~A}$ & $538.4 \mathrm{~B}$ & $49.7 \mathrm{~A}$ & $1.3 \mathrm{AB}$ & $2.21 \mathrm{~A}$ \\
\hline $\mathrm{PP}+0.5 \% \mathrm{TiO} 2$ & $0.89 \mathrm{~A}$ & $0.64 \mathrm{~A}$ & $29.9 \mathrm{~A}$ & $314.5 \mathrm{~A}$ & $47.2 \mathrm{~A}$ & $1.20 \mathrm{~A}$ & $2.02 \mathrm{~A}$ \\
\hline $\mathrm{PP}+1 \% \mathrm{TiO} 2$ & $0.91 \mathrm{AB}$ & $0.91 \mathrm{AB}$ & $30.3 \mathrm{~B}$ & $351.1 \mathrm{~A}$ & $49.4 \mathrm{~B}$ & $1.28 \mathrm{~B}$ & $2.13 \mathrm{~A}$ \\
\hline $\mathrm{PP}+2 \% \mathrm{TiO} 2$ & $0.92 \mathrm{BC}$ & $1.12 \mathrm{~B}$ & $31.2 \mathrm{C}$ & $352.4 \mathrm{~A}$ & $49.5 \mathrm{~B}$ & $1.29 \mathrm{~B}$ & $1.72 \mathrm{~A}$ \\
\hline $\mathrm{PP}+4 \% \mathrm{TiO} 2$ & $0.93 \mathrm{C}$ & $1.21 \mathrm{BC}$ & $31.8 \mathrm{D}$ & $533.7 \mathrm{~B}$ & $51.2 \mathrm{C}$ & $1.41 \mathrm{C}$ & $1.81 \mathrm{~A}$ \\
\hline
\end{tabular}

However, the largest decrease in the tensile modulus of elasticity was determined to be $41.6 \%$ for the $0.5 \%$ nano$\mathrm{TiO}_{2}$ composite. The changes in the flexural strength and the modulus of elasticity at the flexure were determined to have same change trend with tensile strength and tensile modulus. The addition of $4 \%$ nano- $\mathrm{TiO}_{2}$ was found to increase both flexure strength and the modulus of elasticity at the flexure, except for $0.5 \%$ nano- $\mathrm{TiO}_{2}$. The greatest increase in both the flexure strength and the modulus of elasticity at the flexure occurred in the $4 \%$ nano- $\mathrm{TiO}_{2}$ composite. The izod impact strength of all of the composites with nano- $\mathrm{TiO}_{2}$ was less than that of the neat PP. The greatest decrease in the izod impact strength was found to be $22.2 \%$ for the $2 \%$ nano- $\mathrm{TiO}_{2}$ composites. Based on these results, nano- $\mathrm{TiO}_{2}$ was determined to provide a significant improvement in the mechanical properties, such as tensile strength, flexure strength, and the modulus of elasticity at the flexure. However, the tensile modulus of elasticity and the izod impact strength decreased as the amount of added nano- $\mathrm{TiO}_{2}$ increased.

According to the variance analysis and the Duncan test, the differences among the formulations were statistically significant with the increasing loading rates. The inorganic nano-particles improved the mechanical properties of the nanocomposites. Generally, mechanical properties, such as tensile strength, elastic modulus, and stress at break increased, but impact strength and elongation decreased $[1,11,12]$. In one study, it was found that the tensile strength and elastic modulus of the PP composites increased with the addition of the $\mathrm{TiO}_{2}$, but no improvement was observed in the impact strength due to the reduction of toughness [12]. The effect of nanoclays on the mechanical properties of PP composites was investigated in another study, and the results indicated that the mechanical properties of the composites, such as tensile strength, tensile modulus, flexural strength, and flexural modulus, increased as the particle loading increased [13]. In still another study that was conducted to investigate the mechanical properties of polypropylene/titanium dioxide nanocomposites, the mechanical properties of the composites increased when the $\mathrm{TiO}_{2}$ nanoparticles were added [9].

The thermal stability of the composites is an important property for various application areas due to the changes in the viscoelastic behaviour and viscosity [19], so the thermal properties of the composites were investigated by DSC and TGA/DTA. Fig. 2 shows the TGA/DTG curves of the composites. According to the TGA curves in the figure, the addition of nano- $\mathrm{TiO}_{2}$ slightly improved thermal stability of the neat $\mathrm{PP}$, when $\mathrm{TiO}_{2}$ was added in the range of $0 \%$ to $4 \%$. But it was found that the TG curves generally were the same. The DTG curves identified peaks of the composites between 370 and $470{ }^{\circ} \mathrm{C}$ at the value of $2800 \mathrm{mg} / \mathrm{min}$. This peak corresponds to the rupture of the C-C chain's bonds along with H-abstraction at the site of rupture $[14,15]$. $\mathrm{PP}$ is strongly hygroscopic in nature and completely depleted at $426^{\circ} \mathrm{C}$ without the formation of any char residue [16]. Fig. 2 b shows the DTA curves that indicate the degradation point of the neat $\mathrm{PP}$ and the PP composites.

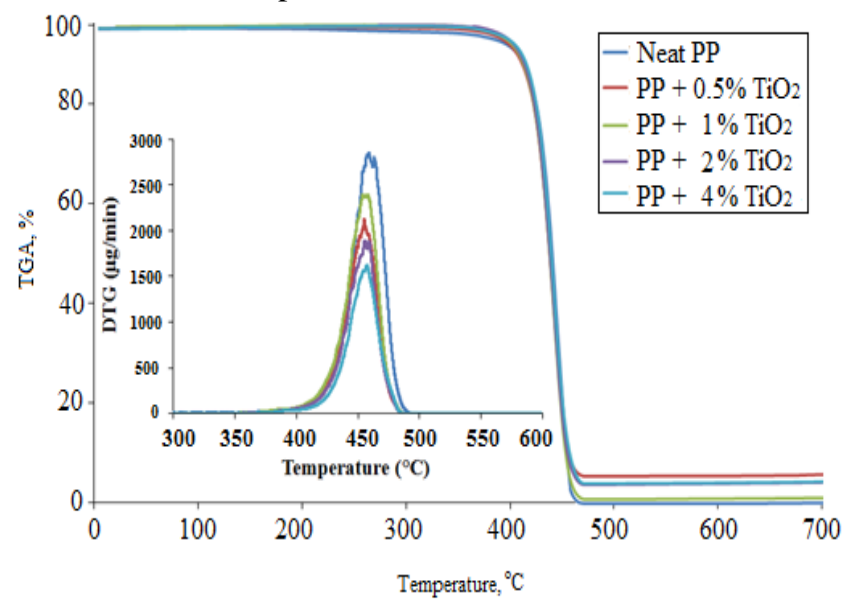

a

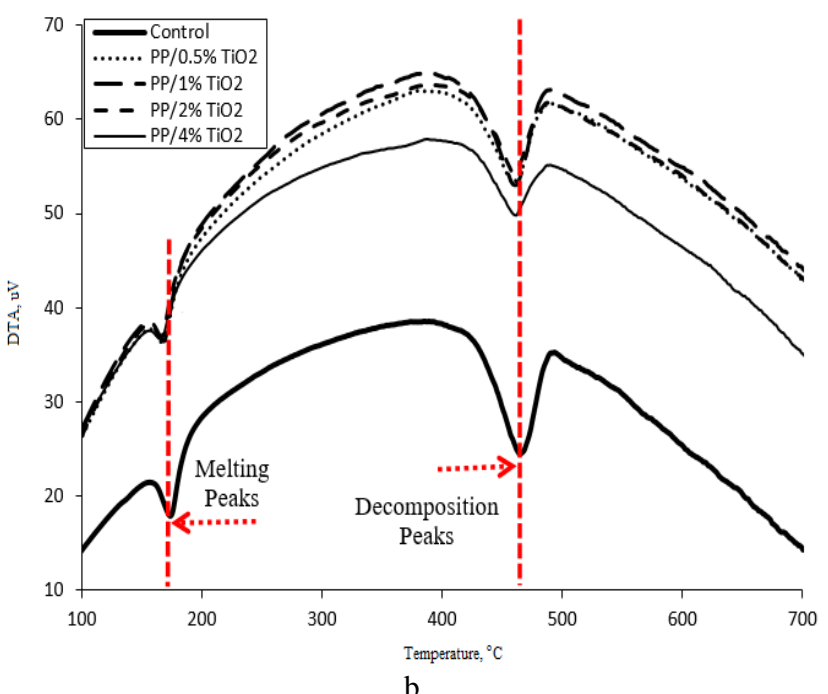

Fig. 2. TG curves of the nanocomposites: $a-T G A / D T G ; b-D T A$

There were two degradation points, i.e., a melting point and a degradation point. The endothermic peaks at 165 and $460{ }^{\circ} \mathrm{C}$ in the DTA curves correspond to the melting point and the degradation point, respectively. Table 3 shows $\mathrm{T}_{\% 10}, \mathrm{~T}_{\% 50}, \mathrm{DTG}_{\max }$, and mass loss of the composites. $\mathrm{T}_{\% 10}, \mathrm{~T}_{\% 50}$, and $\mathrm{DTG}_{\max }$ increased with the addition of the nano- $\mathrm{TiO}_{2}$. The highest degradation 
temperatures were determined to be $436.5^{\circ} \mathrm{C}$ for $\mathrm{T} \% 10$ and $457.3{ }^{\circ} \mathrm{C}$ for $\mathrm{T}_{\% 50}$. The maximum improvement ratio of the degradation temperature was found to be $1 \%$ in the composites with $4 \%$ nano- $\mathrm{TiO}_{2}$ for $\mathrm{T}_{10 \%}$ and $0.5 \%$ in the composites with $4 \%$ nano- $\mathrm{TiO}_{2}$ for $\mathrm{T}_{50 \%}$. The maximum DTG $_{\max }$ value was found to be $461.1^{\circ} \mathrm{C}$ for the composites with $4 \%$ nano- $\mathrm{TiO}_{2}$. The highest improvement ratio in the $\mathrm{DTG}_{\max }$ value was determined to be $0.5 \%$ for the composites with $4 \%$ nano- $\mathrm{TiO}_{2}$.

Table 3. Summary of the TGA curves of the nanocomposites

\begin{tabular}{|l|c|c|c|c|}
\hline \multicolumn{1}{|c|}{ Composites } & $\begin{array}{c}\mathrm{T}_{10 \%,}, \\
{ }^{\circ} \mathrm{C}\end{array}$ & $\begin{array}{c}\mathrm{T}_{50 \%,} \\
{ }^{\circ} \mathrm{C}\end{array}$ & $\begin{array}{c}\mathrm{DTG}_{\max }, \\
{ }^{\circ} \mathrm{C}\end{array}$ & $\begin{array}{c}\text { Mass loss, } \\
\%\end{array}$ \\
\hline $\mathrm{PP}$ & 432.1 & 454.8 & 458.7 & 99.96 \\
\hline $\mathrm{PP} / 0.5 \% \mathrm{TiO}_{2}$ & 433.2 & 455.5 & 458.9 & 99.95 \\
\hline $\mathrm{PP} / 1 \% \mathrm{TiO}_{2}$ & 433.5 & 455.7 & 459.2 & 99.94 \\
\hline $\mathrm{PP} / 2 \% \mathrm{TiO}_{2}$ & 435.4 & 456.3 & 459.4 & 99.86 \\
\hline $\mathrm{PP} / 4 \% \mathrm{TiO}_{2}$ & 436.5 & 457.3 & 461.1 & 99.56 \\
\hline
\end{tabular}

For good interaction, the nanoparticles are capable of restricting the movement of a polymer chain, which makes the scission of the polymer chains more difficult at lower temperatures. As a result, the degradation temperature of the composites shifted to a higher temperature [17]. Table 3 shows that the residue value of neat PP was very close to $0.04 \%$. For the nanocomposites, the residues were found to be about $0.05 \%$ for $0.5 \% \mathrm{TiO}_{2} ; 0.06 \%$ for $1 \% \mathrm{TiO}_{2}$; $0.14 \%$ for $2 \% \mathrm{TiO}_{2}$; and $0.44 \%$ for $4 \% \mathrm{TiO}_{2}$. This shows that the thermal stability of the PP composites was enhanced by the addition of nano- $\mathrm{TiO}_{2}$. Increases in the thermal stability of PP by the addition of various fillers have been reported in literature [9]. Fig. 3 and Table 4 show DSC curves and summary data of the composites with nano- $\mathrm{TiO}_{2}$. Fig. 3 shows that the $\mathrm{Tm}$ values of the composites changed with the addition of nano- $\mathrm{TiO}_{2}$ and the composites have a different $T m$ value.

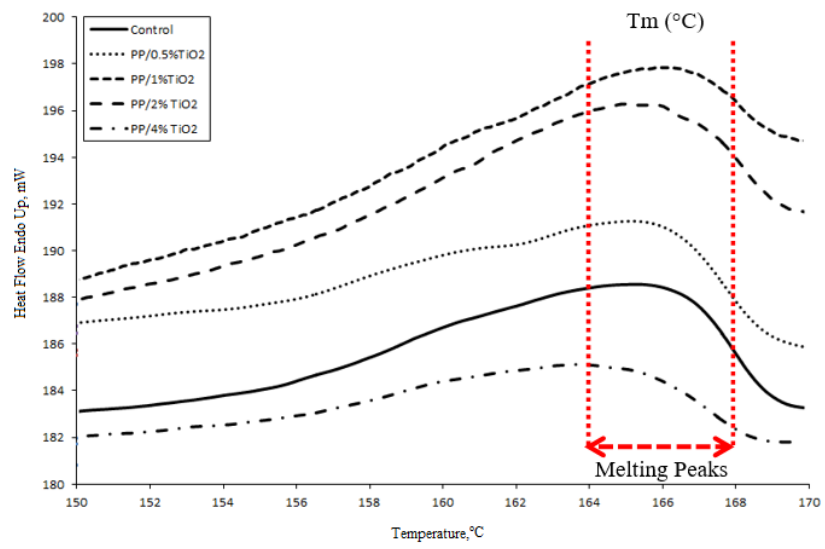

Fig. 3. DSC curves of the nanocomposites during the heating process

Table 4. DSC curves of the nanocomposites

\begin{tabular}{|c|c|c|c|}
\hline Composites & $\mathrm{T}_{m},{ }^{\circ} \mathrm{C}$ & $\Delta \mathrm{H}_{m}, \mathrm{~J} / \mathrm{g}$ & $\mathrm{X}_{c}, \%$ \\
\hline Control & 165.39 & 66.39 & 31.8 \\
\hline $\mathrm{PP} / 0.5 \mathrm{TiO}_{2}$ & 166.25 & 68.75 & 33.1 \\
\hline $\mathrm{PP} / 1 \mathrm{TiO}_{2}$ & 166.55 & 70.15 & 33.9 \\
\hline $\mathrm{PP} / 2 \mathrm{TiO}_{2}$ & 166.98 & 72.35 & 35.3 \\
\hline $\mathrm{PP} / 4 \mathrm{TiO}_{2}$ & 165.88 & 69.54 & 34.7 \\
\hline
\end{tabular}

$\mathrm{T}_{m}$ of the composites did not change very much with the $\mathrm{TiO}_{2}$ loadings. The melting enthalpy $\left(\Delta \mathrm{H}_{m}\right)$ and the degree of crystallinity first increased with the addition of nano- $\mathrm{TiO}_{2}$, reached a maxima of $72.35 \mathrm{~J} / \mathrm{g}$ and $35.3 \%$, respectively, and then decreased for the composite with $4 \%$ nano- $\mathrm{TiO}_{2}$. These results were due to the retarding effect of nano titanium dioxide on the PP crystals and the physical hindrance of the nano- $\mathrm{TiO}_{2}$ particles to the motion of the polymer's molecular chains [16].

In a study, the crystallinity of the neat PP increased when the addition of nano- $\mathrm{TiO}_{2}$ was between 0.5 and $1.5 \%$ because the nanoparticles acted as nucleating agents for PP crystallization. This was probably due to the nucleation role of the nano- $\mathrm{TiO}_{2}$ in the crystallization of $\mathrm{PP}$, which resulted in in a higher degree of crystallinity. After the addition of nano- $\mathrm{TiO}_{2}$, crystallinity for $3 \% \mathrm{TiO}_{2}$ was found decrease because the larger particle aggregates prevented crystal growth. Since the addition of nano- $\mathrm{TiO}_{2}$ is not expected to affect the molecular weight or to cause any chain branching in PP, only the nucleating activity of the nanoparticles was considered in accordance with the literature $[13,18]$. The morphological characterization of the composites was investigated with SEM on both the surface and inside the structure of the samples. The pictures obtained for the surface and the inside structure are shown in Fig. 4.

SEM mapping analysis was also used for the dispersion of nano- $\mathrm{TiO}_{2}$ and the structural analysis of the $\mathrm{TiO}_{2}$ particles, respectively. The SEM images of the surfaces of the composites showed that, generally, there are dispersed particles on the surfaces of the composites. The composites with $0.5,1$, and $2 \%$ nano- $\mathrm{TiO}_{2}$ had fewer agglomerations on the surface; larger and more agglomerations were found on the surfaces of the composites with $4 \%$ nano- $\mathrm{TiO}_{2}$. The fracture SEM images showed the interactions between nano- $\mathrm{TiO}_{2}$, the polymer, and the fillers dispersed in the PP matrix. Some agglomerations were determined in the inner structure of the nanocomposites on the fracture SEM images. It was also noted that there were more agglomerations on the surfaces when the nano- $\mathrm{TiO}_{2}$ loadings were increased. SEM mapping was utilized to determine the dispersion of the nano- $\mathrm{TiO}_{2}$ in the $\mathrm{PP}$ matrix (Fig. 5). The results indicated that the agglomerations increased similarly on the surface and on the fracture side as the loading increased from 0.5 to $4 \%$. When the polymer is blended with nano- $\mathrm{TiO}_{2}$, the blending process should be increased or a lower loading should be used. Mikesova et al. [5] studied the morphology of PP nanocomposites with titanate nanotubes and found that the nanoparticles were dispersed as the smallest crystalline aggregates of irregular shapes on the surfaces of the composites.

In another study, it was found that the interactions between $\mathrm{TiO}_{2}$ and the PP matrix are limited because $\mathrm{TiO}_{2}$ has a polar surface and the polymer has a non-polar surface. But, according to SEM evaluations, nano- $\mathrm{TiO}_{2}$ was found to be almost completely dispersed in the matrix and on the surface, and they behaved like one phase, which shows the good compatibility of the two materials [16]. FTIR analyses were used to determining the chemical structure of the nanocomposites after extrusion (Fig. 6). The FTIR showed that chemical structures of the composites were similar and that there were no major changes among the composites. 

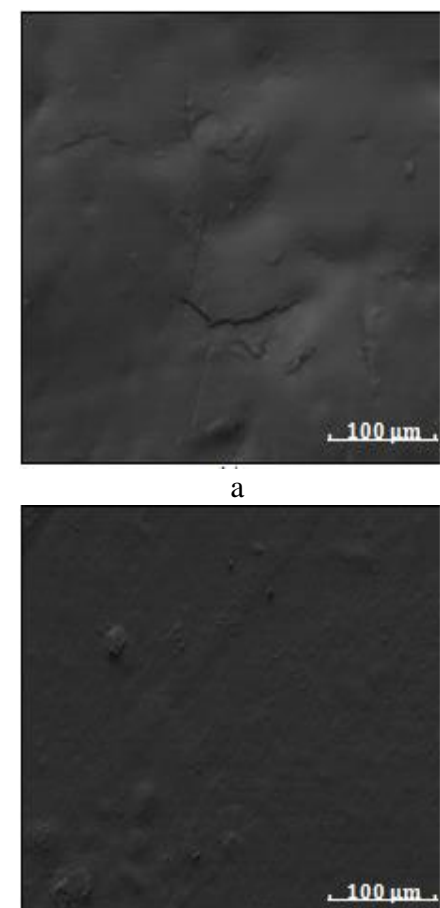

C

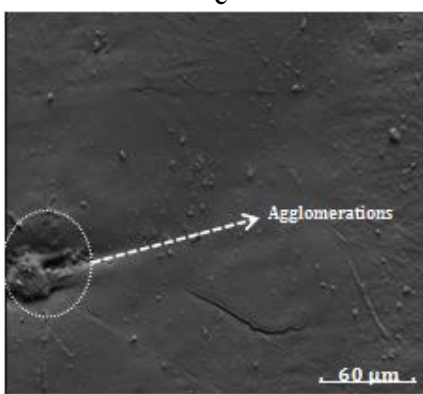

e

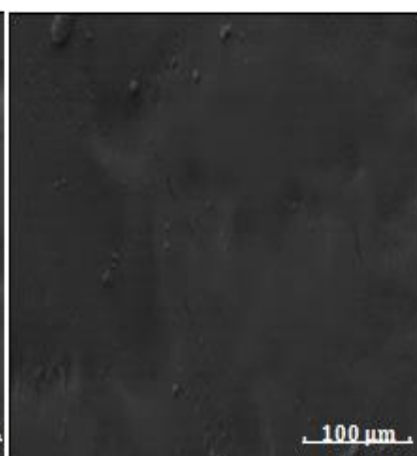

b

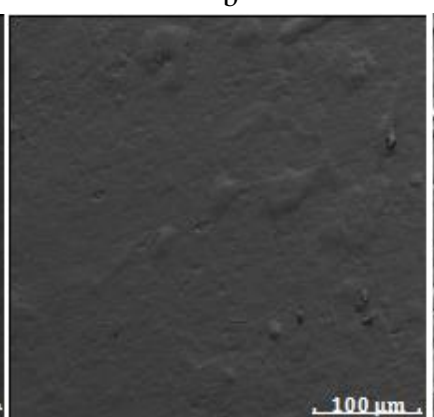

d

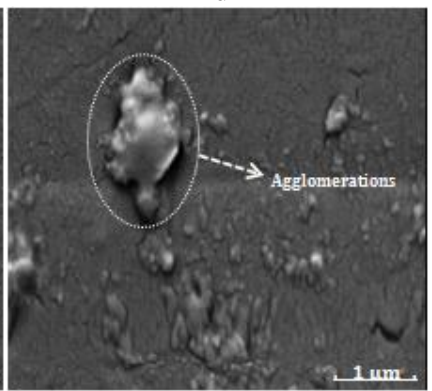

e1

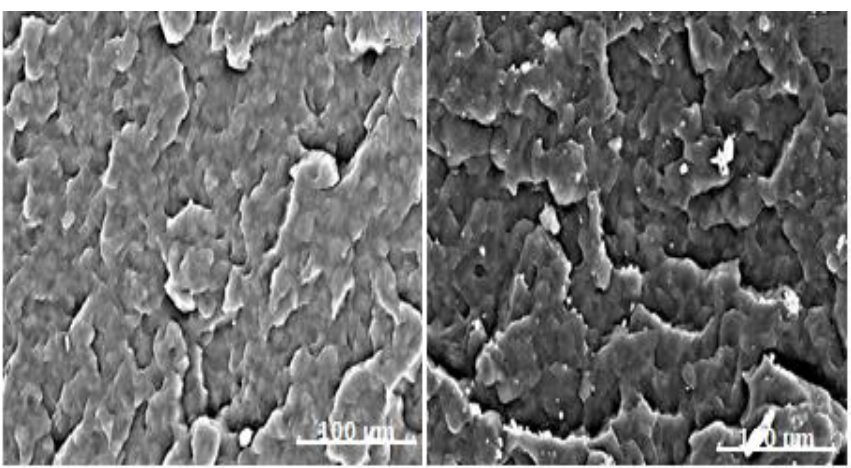

b

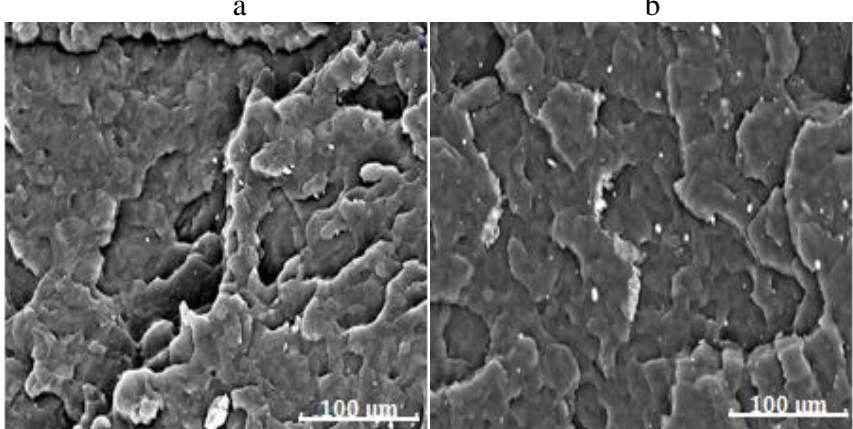

d
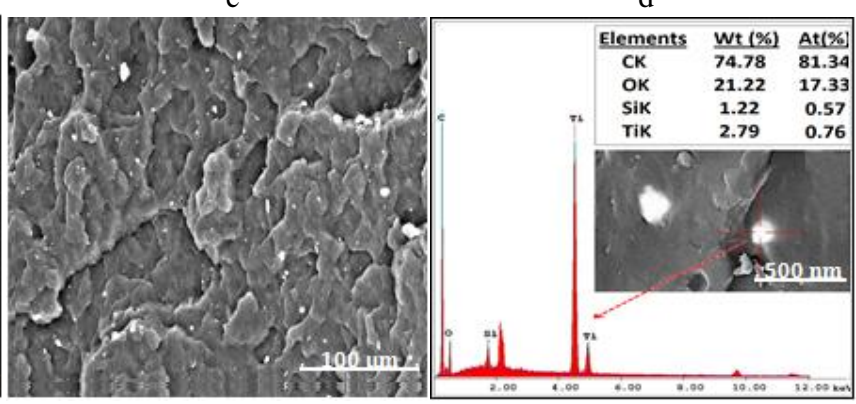

f

Fig. 4. SEM pictures of the surfaces and fractures of the $\mathrm{PP}$ nanocomposites prepared with nano- $\mathrm{TiO}_{2}: \mathrm{a}-\mathrm{pure} \mathrm{PP} ; \mathrm{b}-\mathrm{PP}+0.5 \% \mathrm{TiO}$; $\mathrm{c}-\mathrm{PP}+1 \% \mathrm{TiO}_{2} ; \mathrm{d}-\mathrm{PP}+2 \% \mathrm{TiO}_{2} ; \mathrm{e}, \mathrm{e} 1-\mathrm{PP}+4 \% \mathrm{TiO}_{2} ; \mathrm{f}-\mathrm{SEM} / \mathrm{EDX}$ analysis

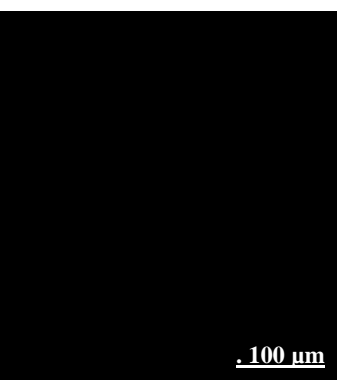

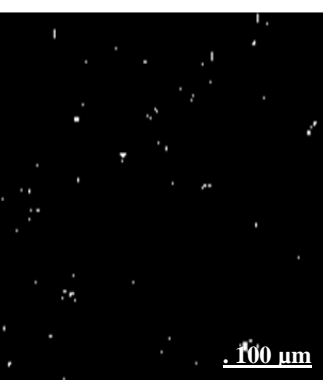

b

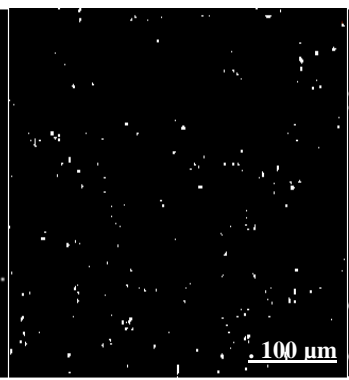

c

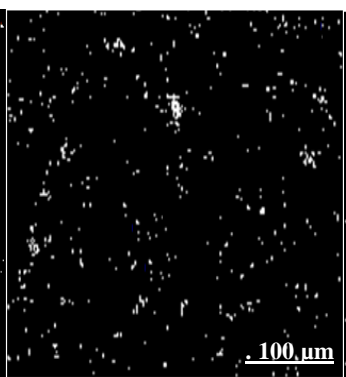

$\mathrm{d}$

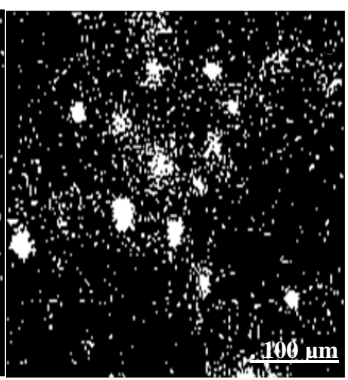

$\mathrm{e}$

Fig. 5. Determination of dispersed particles with SEM mapping of PP nanocomposites prepared with nano-TiO $\mathrm{T}_{2}$ a-pure $\mathrm{PP}$; $\mathrm{b}-\mathrm{PP}+0.5 \% \mathrm{TiO}_{2} ; \mathrm{c}-\mathrm{PP}+1 \% \mathrm{TiO}_{2} ; \mathrm{d}-\mathrm{PP}+2 \% \mathrm{TiO}_{2} ; \mathrm{e}-\mathrm{PP}+4 \% \mathrm{TiO}_{2}$

The intensity of the characteristic peak of PP in the range $2800 \mathrm{~cm}^{-1}$ increased by the addition of $\mathrm{TiO}_{2}$. The broad band centered at $1000-1800 \mathrm{~cm}^{-1}$ is likely due to the vibration of the $\mathrm{Ti}-\mathrm{O}$ bonds in the $\mathrm{TiO}_{2}$ particles. Another broad band between 3500 and $3000 \mathrm{~cm}^{-1}$ was observed, and it related to stretching hydroxyl $(\mathrm{O}-\mathrm{H})$, representing the water as moisture. Several peaks related to $\mathrm{TiO}_{2}$ were observed in all of the samples [19].

\section{CONCLUSIONS}

In this study, we investigated the effects of nano- $\mathrm{TiO}_{2}$ for three different loadings on the properties of polypropylene composites. The results indicated that there were increases in the density and the mechanical properties, such as tensile strength, flexural strength, and the modulus of elasticity at bending. However; the tensile modulus of elasticity and the izod impact strength both decreased. It was found that the thermal stability of the composites improved with the addition of nano- $\mathrm{TiO}_{2}$. The SEM pictures showed that there were some agglomerations in morphological structure of the composites.

Specifically, the agglomerations were found to increase for the high loadings $\left(4 \% \mathrm{TiO}_{2}\right)$. Therefore, in blends prepared with a single-screw extruder, it can be advised 
that a high loading of nano- $\mathrm{TiO}_{2}$ to the polymer matrix should be avoided.

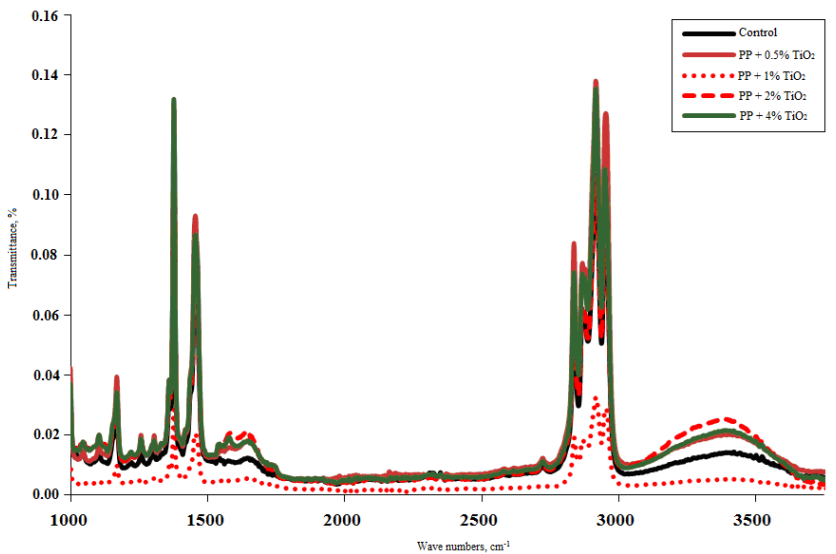

Fig. 6. FTIR spectra of $\mathrm{PP} / \mathrm{TiO}_{2}$ nanocomposites

\section{Acknowledgements}

This study was supported by 2209/A Project Foundation for graduate student provided by the scientific and technological research council of Turkey (TUBITAK).

\section{REFERENCES}

1. Kruenate, J., Tongpool, R. Panyathanmaporn, T. Optical and Mechanical Properties of PP Modified by Metal Oxides Surface and Interface Analysis 36 2004: pp. 1044-1047.

2. Mittal, V. Optimization of Polymer Nanocomposites Properties. Wiley, ISBN: 978-3-527-32521-4, 2010, p. 440. http://dx.doi.org/10.1002/9783527629275

3. Jagannathan, T., Kalathi, U. Y., $\quad$ Kenneth, S. S, Gary, S. G., Sanat, K. K. Nanoparticle Diffusion in Polymer Nanocomposites Physical Review Letters 112 2014: pp. 108301.

4. Altan, M., Yildirim, H. Mechanical and Antibacterial Properties of Injection Molded $\mathrm{PP} / \mathrm{TiO}_{2}$ Nano-Composites: Effects of Surface Modification Journal of Material Science and Technology 28 (8) 2012: pp. 686-692. http://dx.doi.org/10.1016/S1005-0302(12)60116-9

5. Mikesova, J., Slouf, M., Gohs, U., Popelkova, D., Vackova, T., Hung, Vu, N., Kratochvil, J., Zhigunov, A. Nanocomposites of Polypropylene/Titanate Nanotubes: Morphology, Nucleation Effects of Nanoparticles and Properties Polymer Bulletin 71 2014: pp. 795-818.

6. Kubacka, A., Fernández-García, M., Cerrada, M. L., Fernández-García, M. Nano-Antimicrobials: Progress and Prospect: In Titanium Dioxide-Polymer Nanocomposites with Advanced Properties. Springer, 2012: pp. 119-149.

7. Yang, C., Wu, Y., Liu, C. Studies on Crystallizations and Mechanical Properties of Polypropylene/nano- $\mathrm{TiO}_{2}$
Composites. Material Design, Processing and Applications, Parts 1-4 690-693 2013: 494-498

8. Zohrevand, A., Ajji, A., Mighri, F. Morphology and Properties of Highly Filled $\mathrm{PP} / \mathrm{TiO}_{2}$ Nanocomposites. Polymer Engineering and Science, 2013: pp. 874-886.

9. Esthappana, S. K., Kuttappan, S. K, Joseph, R. Thermal and Mechanical Properties of PP/Titanium Dioxide Nanocomposite Fibers Materials and Design 37 2012: pp. $537-542$. http://dx.doi.org/10.1016/j.matdes.2012.01.038

10. Niska, K. O., Sain, M. Wood Polymer Composites. CRC Press, NewYork, Washington D.C, 2008: p. 352.

11. Olmos, D., Dominguez, C., Castrillo, P. D., GonzalesBenito, J. Crystallization and Final Morphology of HDPE: Effect of High Energy Ball Milling and the Presence of $\mathrm{TiO}_{2}$ Nano Particles Polymer 50 2009: pp. 1732-1742.

12. Altan, M., Yildirim, H. Mechanical and Morphological Properties of Polypropylene and High Density Polyethylene Matrix Composites Reinforced with Surface Modified Nano Sized $\mathrm{TiO}_{2}$ Particles World Academy of Science, Engineering and Technology 4 2010: pp. 10-26.

13. Rahman, N. A., Hassan, A., Yahya, Y., LafiaAraga, R. A. Glass Fiber and Nanoclay Reinforced Polypropylene Composites: Morphological, Thermal and Mechanical Properties Sains Malaysiana $42(4)$ 2010: pp. 537-546.

14. Joseph, P. V., Joseph, K., Thomas, S., Pillai, C. K. S., Prasad, V. S., Groeninckx, G., Sarkissova, M. The Thermal and Crystallization Studies of Short Sisal Fiber Reinforced Polypropylene Composite Composite: Part A 34 (3) 2003: pp. 253-266. http://dx.doi.org/10.1016/S1359-835X(02)00185-9

15. Daniel, J. R. Encyclopedia of Polymer Science and Engineering. $2^{\text {nd }}$ Edition, John Wiley, New York, 1985: p. 268.

16. Khan, J. A., Khan, M. A., Islam, R., Gafur, A. Mechanical, Thermal and Interfacial Properties of Jute Fabric-Reinforced Polypropylene Composites: Effect of Potassium Dichromate Materials Sciences and Applications 1 2010: pp. 350-357.

17. Yang, F., Nelson, G. L. Polymer/silica nanocomposites prepared via extrusion Polymer Advance Technology 17 2006: pp. 320-326.

18. Bikiaris, D. N., Papageorgiou, G. Z., Pavlidou, E., Vouroutzis, N., Palatzoglou, P., Karayannidis, G. P. Preparation by Melt Mixing and Characterization of Isotactic $\mathrm{PP} / \mathrm{SiO}_{2}$ Nanocomposites Containing Untreated and Surfacetreated Nanoparticles Journal of Applied Polymer Science 100 2006: pp. 2684-2696.

19. Mouritz, A. P., Gibson, A. G. Fire Properties of Polymer Composite Materials. Springer, ISBN-10:1-4020-5355-X, 2006: p. 401. 